\title{
A systematic review and synthesis of theories of change of school-based interventions integrating health and academic education as a novel means of preventing violence and substance use among students
}

Tara Tancred ${ }^{1}$ (D), Sara Paparini ${ }^{1}$, G. J. Melendez-Torres² ${ }^{2}$ James Thomas $^{3}$, Adam Fletcher ${ }^{4}$, Rona Campbell ${ }^{5}$ and Chris Bonell ${ }^{1 *}$

\begin{abstract}
Background: Schools can play an important role in promoting health. However, many education policies and institutions are increasingly emphasising academic attainment targets, which appear to be diminishing the time available for health education lessons. Interventions that integrate both health and academic learning may present an ideal solution, simultaneously addressing health education and academic development. The theories of change underlying these interventions are therefore of interest, but are poorly studied.

Methods: A systematic review of evaluations of interventions that integrate academic and health education for reduced substance use and/or violence was carried out. As part of this, reports describing theory were assessed for quality and data extracted. Theoretical data were synthesised within and across individual interventions using reciprocal translation and meta-ethnographic line of argument synthesis to produce an overall theory of change for interventions that integrate health and academic education to prevent substance use and violence.

Results: Forty-eight reports provided theoretical descriptions of 18 interventions. An overarching theory that emerged was that eroding 'boundaries' at multiple and mutually reinforcing levels - by integrating academic and health education, by transforming relationships between teachers and students, by generalising learning from classrooms to the wider school environment and by ensuring consistent messages from schools and families -is intended to lead to the development of a community of engaged students oriented towards pro-social behaviour and away from substance use, violence and other risk behaviours.

Conclusions: Eroding 'boundaries' between health and academic education, teachers and students, classrooms and the wider school and schools and families were seen to be the most critical to establishing new frameworks of family, classroom or school organisation that are conducive to promoting both academic and social-emotional outcomes. Whether such interventions are feasible to implement and effective in reducing risk behaviours will be examined in other reports arising from the review.
\end{abstract}

Keywords: Adolescent health, Prevention, Education, Qualitative research, Theory, Systematic review

\footnotetext{
* Correspondence: chris.bonell@lshtm.ac.uk

${ }^{1}$ Department of Public Health, Environments and Society, London School of

Hygiene and Tropical Medicine, 15-17 Tavistock Place, London WC1H 9SH,

UK

Full list of author information is available at the end of the article
}

(c) The Author(s). 2018 Open Access This article is distributed under the terms of the Creative Commons Attribution 4.0 International License (http://creativecommons.org/licenses/by/4.0/), which permits unrestricted use, distribution, and reproduction in any medium, provided you give appropriate credit to the original author(s) and the source, provide a link to the Creative Commons license, and indicate if changes were made. The Creative Commons Public Domain Dedication waiver (http://creativecommons.org/publicdomain/zero/1.0/) applies to the data made available in this article, unless otherwise stated. 


\section{Background}

Schools can play a critical role in improving young people's health [1-5]. Given the emphasis in many education policies and institutions on academic attainment targets and diminished time for health education [6-10], interventions which combine health and academic education have sought a platform within academic curricula $[11,12]$. Such programmes tend to focus on social and emotional learning, recognising the mutually reinforcing benefits between the development of social and emotional skills and academic outcomes through an interplay of cognitive and non-cognitive skill development [13, 14].

Young people's use of substances (alcohol, tobacco and other drugs) is an important public health issue [15]. Alcohol use is associated with unsafe sexual behaviour, unintended pregnancies, accidents/injuries and violence [16]. Of smokers, 40\% start in secondary school [17] and early initiation is associated with heavier and more enduring smoking and greater mortality. Young people's drug use is associated with accidental injury, self-harm, mental ill health and suicide [18-20], and other 'problem' behaviours [15, 21-24].

The prevalence, harms and costs of violence among young people mean that addressing this is a public health priority $[25,26]$. By age $15-16,24 \%$ of students report that they have carried a weapon and 19\% reported attacking someone with the intention to hurt them seriously [27]. There are links between aggression and anti-social behaviours in youth and violent crime in adulthood [28, 29].

Many of the programmes integrating health and academic education aim to reduce violence or substance use, with potentially synergistic effects due to shared risk factors [30-32]. These programmes may allow for a larger intervention 'dose' and may provide opportunities for reinforcement of learning across subjects [33-35]. While delivered primarily in the classroom, many such programmes also seek to improve the overall school culture and some extend their reach to parents and carers, engaging them in reinforcing and modelling behaviour and skills taught in the classroom.

Several authors have previously drawn together descriptions of the theoretical aspects of social and emotional skills programmes, some of which aim to be integrated with academic teaching. For example, Flay et al. [36] suggest key common aspects across such programmes' conceptual frameworks, including the need for change in the school-wide climate, training of staff and students in behavioural and environmental considerations, providing opportunities for social modelling, provision of direct instruction and parent and community involvement. Haegerich and Metz [37] drew out a common conceptual framework that outlines how developing social and emotional competencies might improve behaviours, which then positively influence academic outcomes. This framework also emphasises the importance of the interventions affecting school climate, suggesting they can impact students' feelings of connectedness to their school settings, safety when at school and parental involvement, also contributing to improved behaviours and academic outcomes. Of note, however, is that these reviews were not systematic and do not clearly distinguish between interventions that do or do not aim for the integration of social and emotional learning with academic education.

To our knowledge, there have been no systematic reviews of programmes that integrate academic and health education. Therefore, there is limited available information on the effectiveness of these programmes, the theories of change that drive them or the factors that may affect their implementation. Understanding theory is critical for effective programme development [38, 39]. Interventions that integrate academic and health education for reduced substance use and/or violence have not previously been identified in the literature as a discrete category. Therefore, before synthesising evidence on process and outcomes, a distinctive theory of change must be established. Assuming the existence of a distinctive theory of change, it is then possible to define the intended mechanisms of the intervention and hypothesise how these might interact with context to generate outcomes. We will thus start the process of developing a realist theory of change, refining this via the synthesis of process evaluations and data allowing it to be tested via the synthesis of outcome evaluations.

As a first step, and within the context of a broader systematic review also synthesising evidence from process and outcome evaluations of school-based interventions that integrate health and academic education to reduce violence or substance use among children and young people, we used meta-ethnographic methods to synthesise theories of change for such interventions. We present the results of that synthesis here.

\section{Methods}

\section{Synthesising theory: some key considerations}

Methodological challenges and opportunities posed by syntheses of theories of change have previously been noted [40-43]. Methods for theory synthesis tend to draw on methodological approaches to synthesising empirical qualitative data (or 'qualitative synthesis') [44]. Qualitative synthesis, in turn, draws mainly from qualitative data analysis [45]. Broadly, common principles and practices apply to different approaches to qualitative analysis and synthesis, including data immersion, an emphasis on depth, iterative coding of recurrent themes or concepts, consensus-reaching among multiple researchers and the purposive inclusion of 'deviant' cases in the analysis [46]. 
Although there have been some attempts at developing and using checklists to appraise the quality of theories of change [40], there is no single well-established tool [47]. There are also challenges when applying methods used to synthesise empirical qualitative data (generally context-specific) to the synthesis of theory (often abstracted from context) [48]. However, we considered that synthesis can be achieved, for example, by treating theory data as primary data in itself [40]. Previous studies have used meta-ethnography to synthesise non-ethnographic data $[40,48,49]$. This approach was the one we took to synthesise theories of change here. Further, we considered that meta-ethnography would be appropriate for the literature on interventions that integrate health and academic curricula, as this is a fairly cohesive field of study [41]. Finally, it is a method that enables conceptual synthesis, making it particularly suitable for theory synthesis.

These challenges and considerations informed our use of a two-stage synthesis process-coding and synthesising theories of change within intervention studies, then across them-prior to the development of a line of argument' synthesis that could offer a representation of theoretical constructs in 'different stages along the same causal pathway' ([47], p. 8). This process is described in detail in the methods of theory synthesis section below.

\section{Methods of systematic review}

A full protocol outlining the methods of this systematic literature review, which followed the Preferred Reporting Items for Systematic Reviews and Meta-Analyses (PRISMA) guidelines [50], is available: https://www.journalslibrary.nihr.ac.uk/programmes/phr/145215/\#/ The study was registered with the PROSPERO registry of vsystematic reviews (reference 2015:CRD42015026464) available from: http://www.crd.york.ac.uk/PROSPEROFILES/26464_PROTOCOL_20160011.pdf. Briefly, a systematic review was undertaken of evaluations of school-based interventions delivered: within classroom settings; in regular school hours; and through (at least in part) the integration of academic and health education aiming to prevent substance use or violence among children and young people age 5-18 years. Included studies were process evaluations or outcome evaluations, the latter employing random allocation to intervention and control groups (implementing usual or no treatment), with no restrictions by country. Descriptions of theory of change within, or otherwise linked to, empirical evaluations were synthesised. From November to December 2015, various health, social science and education databases were searched (please see protocol for full listing). Searching of webpages and reference lists of relevant studies for further references and consultation with experts in this field followed. Searches were updated using
PsycINFO and the Cochrane Central Register of Controlled Trials. Searches relating to outcome evaluations of interventions targeting violence were updated on 28 February 2018 and those relating to outcome evaluations of interventions addressing substance use were updated on 14 May 2018. Searches for process evaluations were updated on 8 September 2018.

These are listed in Table 1.

\section{Data extraction}

Data were extracted from all included reports featuring theories of change. Reports that included very minimal information on theory or merely repeated information on theory present in previously published reports already included in our review were excluded and only the earliest report presenting this information was included. All reports that added new understanding of the theoretical basis for an intervention were included. Data extraction included basic study information (e.g. location, duration, participant characteristics, intervention description) as well as theory (e.g. a description of integration of health and academic education, existing theories referred to and description of any theories of change, logic models, conceptual frameworks, or underlying theoretical assumptions pertaining to how the interventions were expected to function).

\section{Quality appraisal}

All reports were assessed for quality using a tool adapted from a previous review [41]. This tool assessed the clarity of constructs and of the relationships between these constructs, whether the theory was logical, based on any prior evidence and potentially testable empirically, whether the theory was developed in concert with practitioner or community stakeholders and whether the theory appeared to be potentially applicable to different contexts. Overall, there were ten indicators of quality, and two reviewers independently judged whether those were present or absent based on the study's description of theory. See Table 2 for a summary of our quality appraisal of included studies. This process aimed to enable us to give greater weight to those reports with a more robust description of theory.

\section{Methods of theory synthesis}

As a preliminary step, each individual intervention theory was subjected to within-intervention coding and synthesis. These theories were then synthesised across all interventions to explore points of reciprocal resonance, refutation and/or complementarity among them. This approach led us to generate a line of argument within the 'across intervention' theory synthesis. 


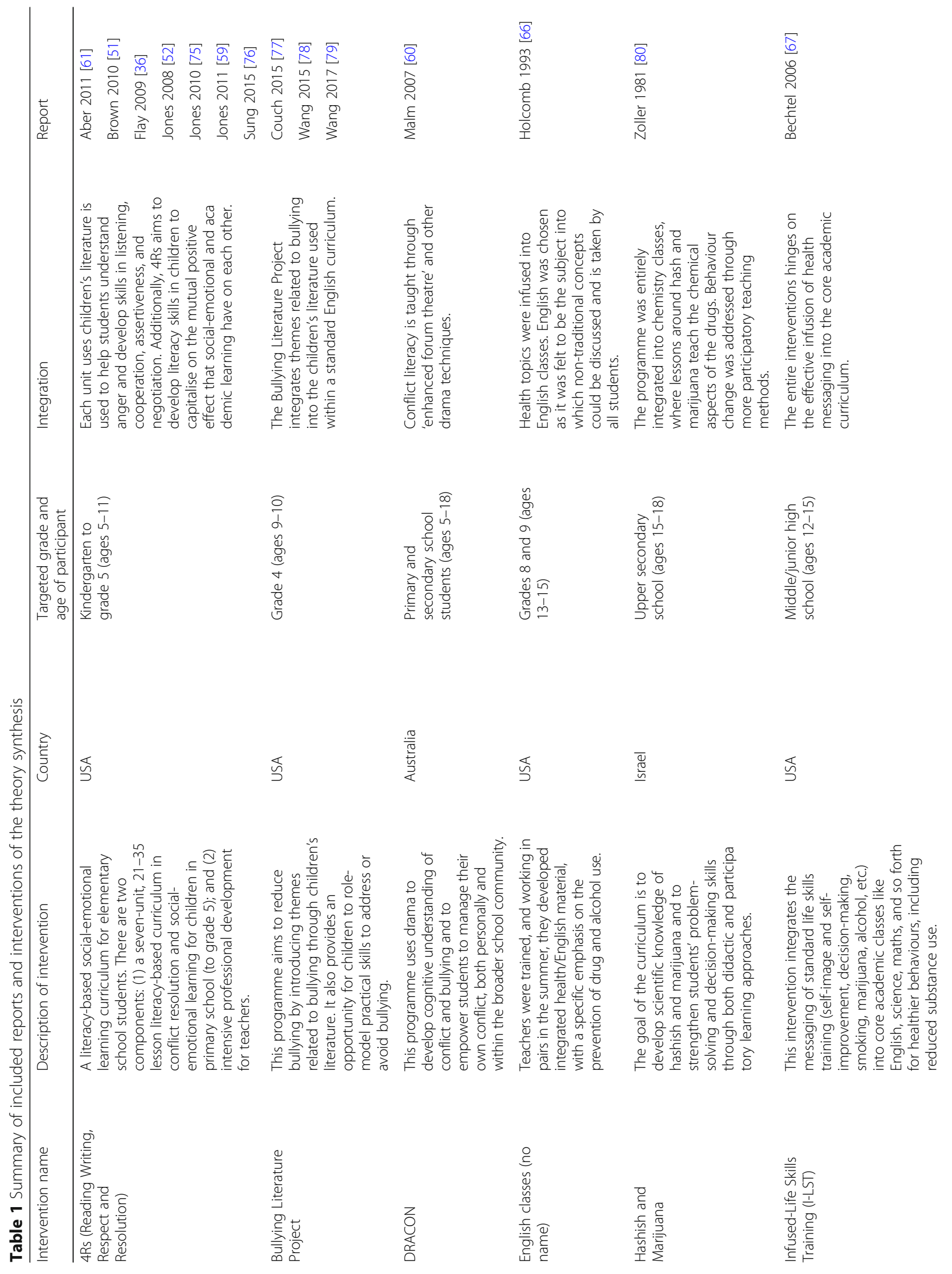




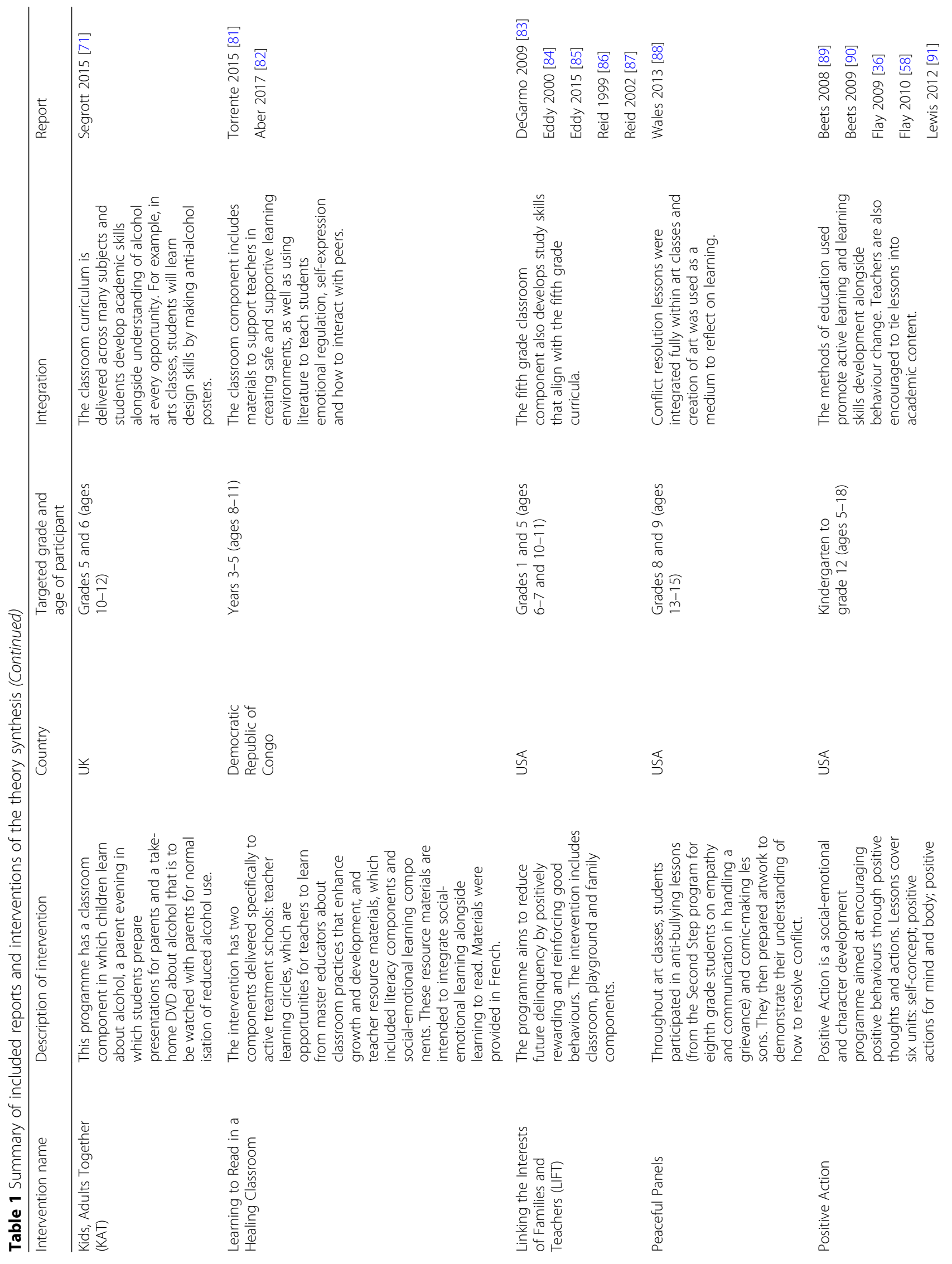




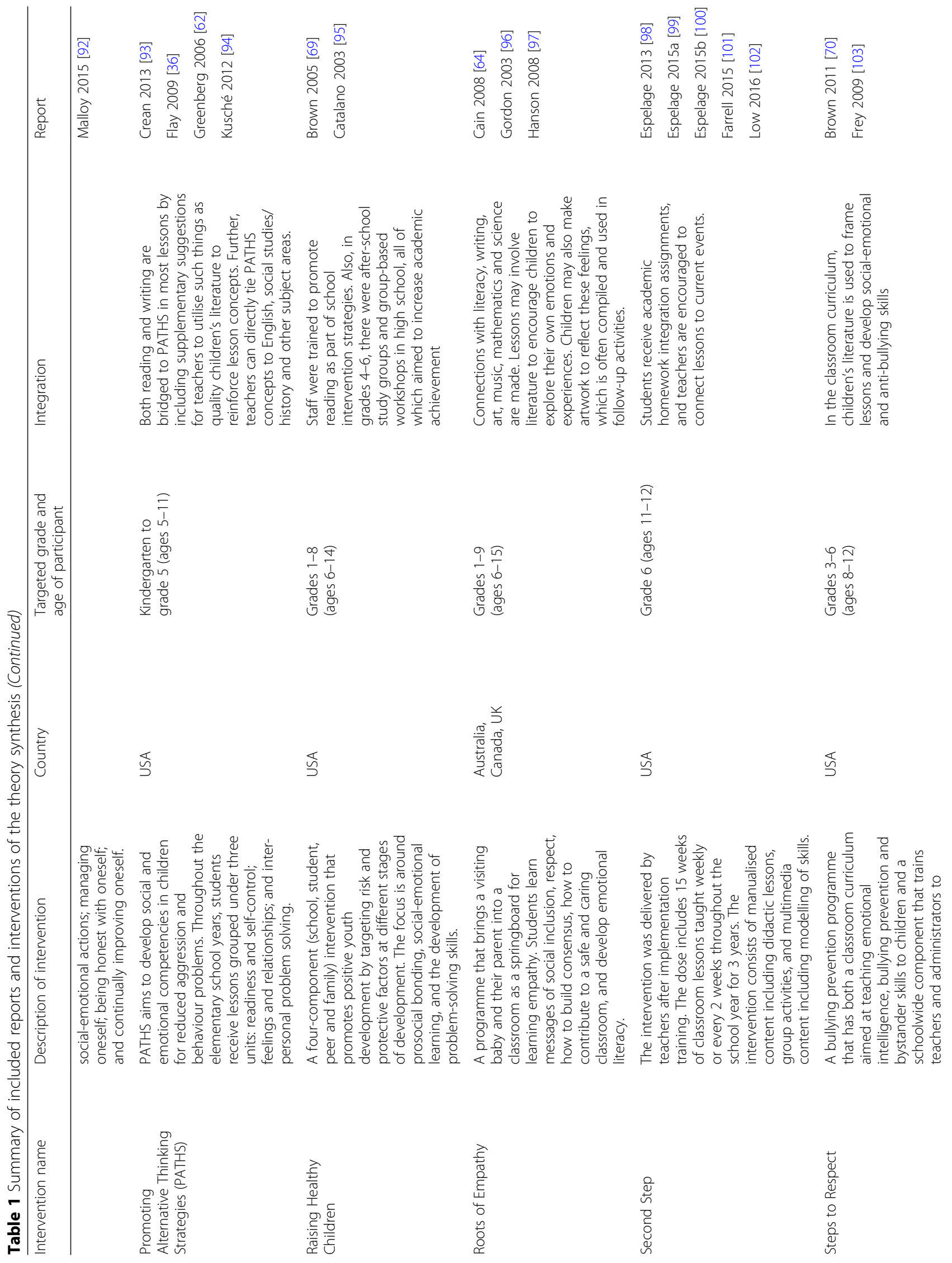




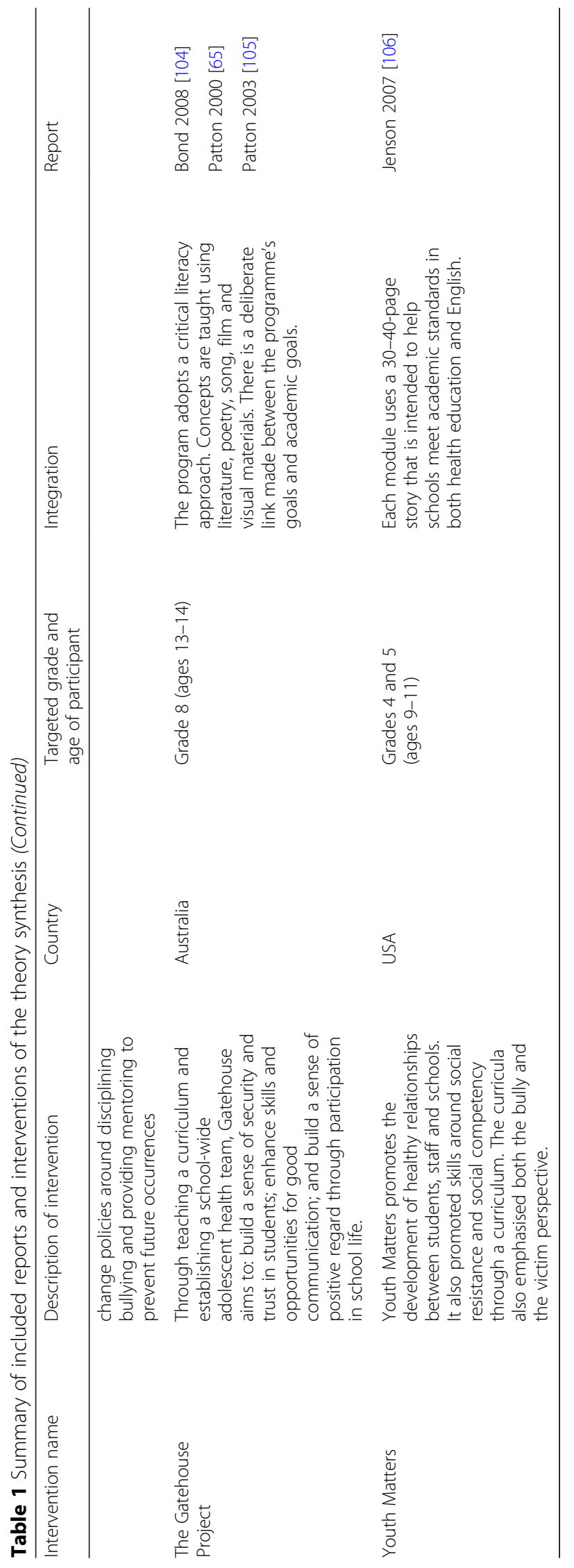




\section{Within-intervention coding}

To pilot our procedures, two higher quality (i.e. having quality scores above $50 \%$, please see Table 2) 'pilot' studies by different authors but focused on the same intervention were read and re-read by two reviewers [51, 52]. Line-by-line codes were applied and memos written up to capture and explain the content of the descriptions of theory. Codes were then grouped, organised in frameworks and exchanged and compared among reviewers to develop an overall set of codes. This set of codes was then applied to the remaining study reports of the intervention in question including description of theory of change. Reviewers kept track of and compared any modifications to the coding framework made from the coding of subsequent studies. Having judged that this piloted process was appropriate, this process was then applied to each intervention in the review.

\section{Within-intervention synthesis}

The next step in the analysis was to synthesise programme theories for each individual intervention. This later allowed us to build on these to develop an overall synthesis, which is the main focus of this paper [48]. For the within-intervention synthesis, reciprocal translation, a dynamic, iterative process where concepts from each report were 'translated' into one another, was used [48, 53, 54]. We identified commonalities, differences of emphasis and contradictions between multiple papers reporting on each intervention's theory, collated sets of codes from the two reviewers and resolved any apparent inconsistencies by discussion or refinement of the emerging synthesis. A third reviewer helped achieve reconciliation, where necessary, and discussed and triangulated the analysis. Where only one report described theory for an intervention, it was taken to represent the theory for that intervention.

\section{Across-intervention synthesis}

We employed a meta-ethnographic approach in the third phase of analysis to synthesise individual programme theories' mechanisms of change to develop a line of argument, as far as possible, for the overall category of intervention that integrates health and academic education to prevent substance use and violence. In this approach, the key concepts extracted during the first (within-intervention) coding exercise were treated as first-order constructs [55] because they reflected closely the authors' opinions and views of the world, rather than being their interpretation of empirical data, which could have been considered as second-order constructs, as in most qualitative syntheses [40,56]. Our first-order constructs appear in the first column of Table 3. Second-order constructs were then generated, which were our interpretation of authors' views. Finally, third-order constructs were developed to produce a line of argument that aimed to describe the overall mechanisms of change taking place within these interventions.

Developing a line of argument was challenging because programme theories described similar notions, but at times offered limited explanation for key concepts and assumptions, so our second-order constructs already entailed a significant degree of abstraction. In working towards our third-order constructs, it was useful to draw from existing theoretical frameworks to develop a coherent overall view of what initially appeared to be disparate concepts. In particular, the notion of 'boundary erosion' (put forward by Markham and Aveyard [57] as a key process to promoting health in schools) was applied, which sensitised us to ways in which concepts from the individual syntheses could be synthesised into a set of third-order constructs to develop an overall line of argument. These are detailed in the third column in Table 3.

A few themes did not fit with the concept of boundary erosion as presented by Markham and Aveyard. These stimulated us to refine and expand the concept of boundary erosion so that it could encompass these apparently divergent themes [54]. These are presented alongside our line-of-argument synthesis in the Discussion section.

Table 3 was adapted from Britten et al.s worked example of meta-ethnography [53] and was used and modified repeatedly by two reviewers to build up the line of argument of the overall synthesis of the theory of change for the interventions included in our systematic review, expressed in the final column.

\section{Results}

Our original searches generated 76,979 unique titles and abstracts that were screened for possible inclusion in the study. From these, we identified 62 relevant reports in this study, of which 39 included some description of theory of change, covering 16 different interventions. Updated searches for outcome evaluations retrieved an additional 2355 and 1945 references, yielding an additional six reports of outcome evaluations. Those for process evaluations retrieved an additional 1552 references yielding an additional three reports of process evaluations. All nine studies included some description of theories of change. Figure 1 reports on the screening procedure for the overall review, indicating which study reports were included in the syntheses of theories of change, as well as the process and outcome evaluations from which these were drawn. Table 1 below summarises the reports that were quality assessed and data extracted for this review. Flay et al. [36] describes three interventions and is therefore repeated, so there are a total of 48 unique reports. Together, these reports provided the theoretical description of 18 of the interventions included in the overall systematic review. 
Tancred et al. Systematic Reviews

(2018) 7:190

Page 9 of 22

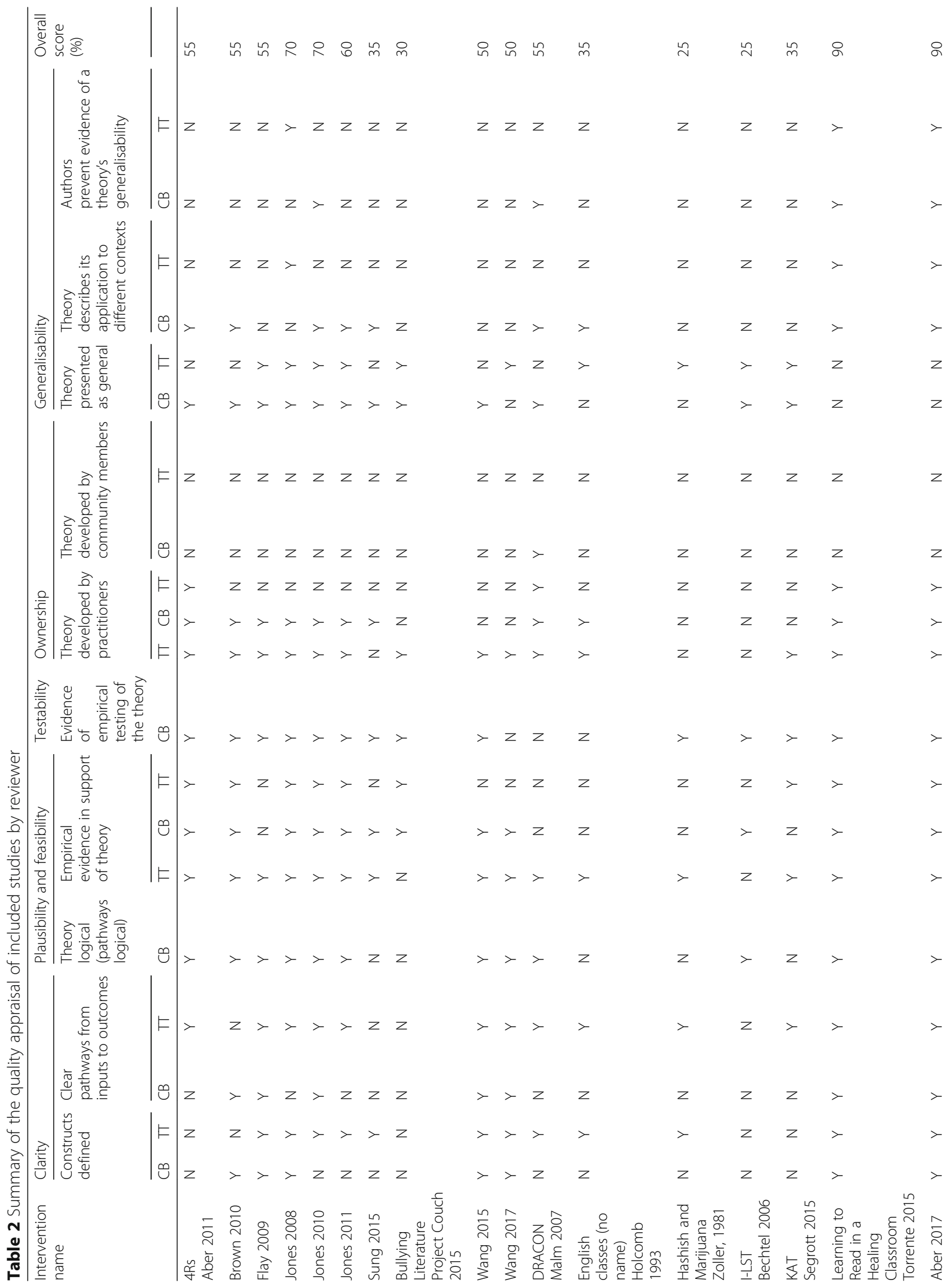




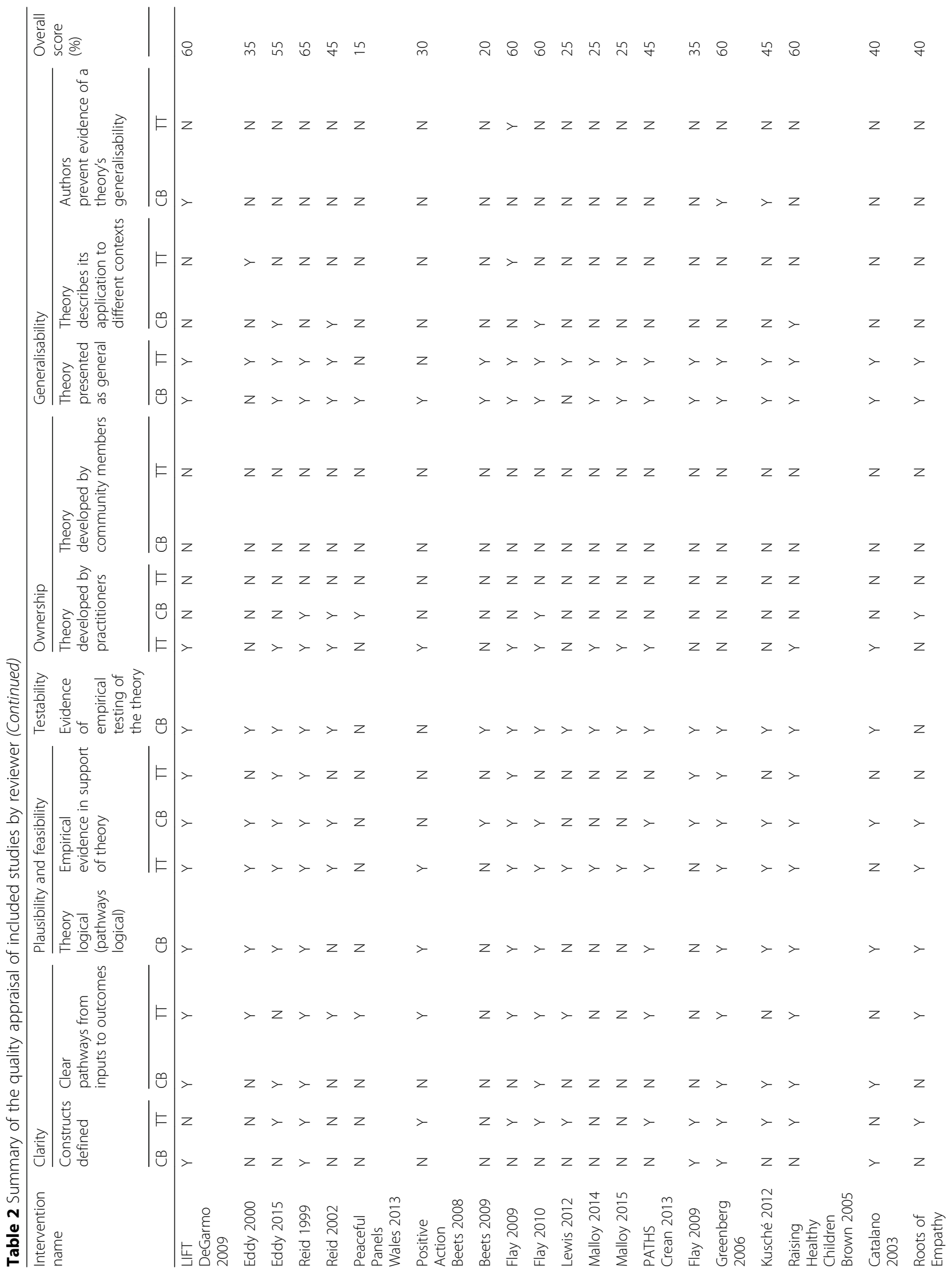


Tancred et al. Systematic Reviews

(2018) 7:190

Page 11 of 22

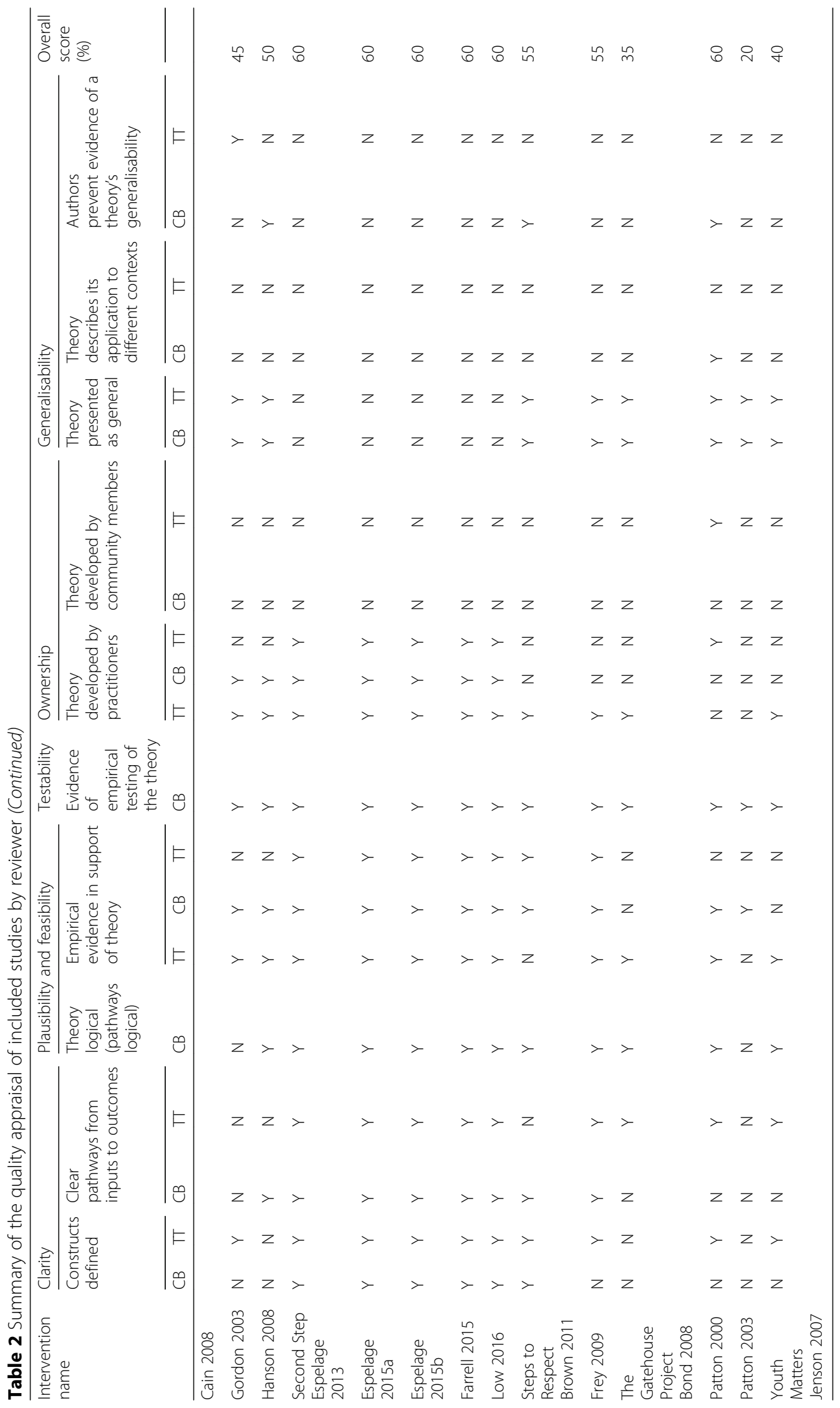


Table 3 First-, second- and third-order constructs

\begin{tabular}{|c|c|c|c|}
\hline First-order constructs & Second-order constructs & $\begin{array}{l}\text { Third-order } \\
\text { constructs }\end{array}$ & $\begin{array}{l}\text { Overall social/psychological process } \\
\text { (line of argument) }\end{array}$ \\
\hline $\begin{array}{l}\text { Academic platform used to simultaneously } \\
\text { build academic and health skills }\end{array}$ & \multirow{2}{*}{$\begin{array}{l}\text { Degree of integration of } \\
\text { academic and health } \\
\text { curricula (full or partial) }\end{array}$} & \multirow{4}{*}{$\begin{array}{l}\text { Eroding boundaries } \\
\text { between health and } \\
\text { academic education }\end{array}$} & \multirow{4}{*}{$\begin{array}{l}\text { Eroding boundaries at multiple and } \\
\text { mutually reinforcing levels_-by integrating } \\
\text { academic and health education, by } \\
\text { promoting stronger, more affective } \\
\text { relationships between teachers and } \\
\text { students, by generalising learning from } \\
\text { classrooms to the wider school } \\
\text { environment, and by ensuring consistent } \\
\text { messaging between schools and } \\
\text { families - will lead to the development of a } \\
\text { community of engaged students oriented } \\
\text { towards pro-social behaviour and away } \\
\text { from substance use, violence and other } \\
\text { risk behaviours. }\end{array}$} \\
\hline $\begin{array}{l}\text { Health curricula bridged into academic } \\
\text { curricula, with academic curricula } \\
\text { sometimes intended to reinforce health } \\
\text { messages and vice versa }\end{array}$ & & & \\
\hline $\begin{array}{l}\text { Decreasing time during the school day for } \\
\text { health education due to an emphasis on } \\
\text { academic achievement (measured through } \\
\text { standardised test scores) }\end{array}$ & $\begin{array}{l}\text { Pragmatic rationale for } \\
\text { integration }\end{array}$ & & \\
\hline $\begin{array}{l}\text { Mutually reinforcing effect of improved } \\
\text { academic and health outcomes }\end{array}$ & $\begin{array}{l}\text { Scientific rationale for } \\
\text { integration }\end{array}$ & & \\
\hline
\end{tabular}

Students being less resistant to health Additional rationale for messaging in integrated curricula integration

Integrated curriculum providing

opportunities for repetition

Opportunities for experiential learning provided

Teachers' internalisation of curriculum's messages

Teachers' role-modelling of curriculum's promoted behaviours

Forming bonds between prosocial peers and adults and acceptance of behaviours demonstrated within these relationships

Establishment of good relationships between students and teachers

Rewards for prosocial behaviours being given to students

Students internalising prosocial beliefs and feeling positive about themselves following the demonstration of prosocial behaviours, leading to more prosocial behaviours

Students having the opportunity to practice valued skills at multiple levels

A sense of connectedness and bonding with the school is linked to overall emotional wellbeing and security experienced by students in schoo

Connectedness to school fosters better academic learning as the school becomes a more positive environment that students are invested in

Role modelling of prosocial behaviours at home

Parents aware of curricula and expect prosocial behaviours (e.g. conflict resolution skills) to be practiced at home
Normalisation of prosocial behaviours through teacher internalisation of curricula

Establishing student connectedness to the classroom through positive teacher-student relationships

Positive reinforcement of prosocial behaviours

Establishing student connectedness to the school
Eroding boundaries between teachers and students
Eroding boundaries between classroom and the wider school
Normalisation of prosocial behaviours

Provision of opportunities for practical skill development

\section{Study quality}

Table 2 below summarises the quality appraisal of the components of each report included in this study that emphasised theory. The combined appraisal for each study ranged from quite poor (20\% of quality indicators judged to be present by reviewers) to very good (90\% of quality indicators judged to be present by reviewers). There was some disagreement between the two reviewers carrying out the quality assessment, with an overall agreement rate of $71 \%$. 


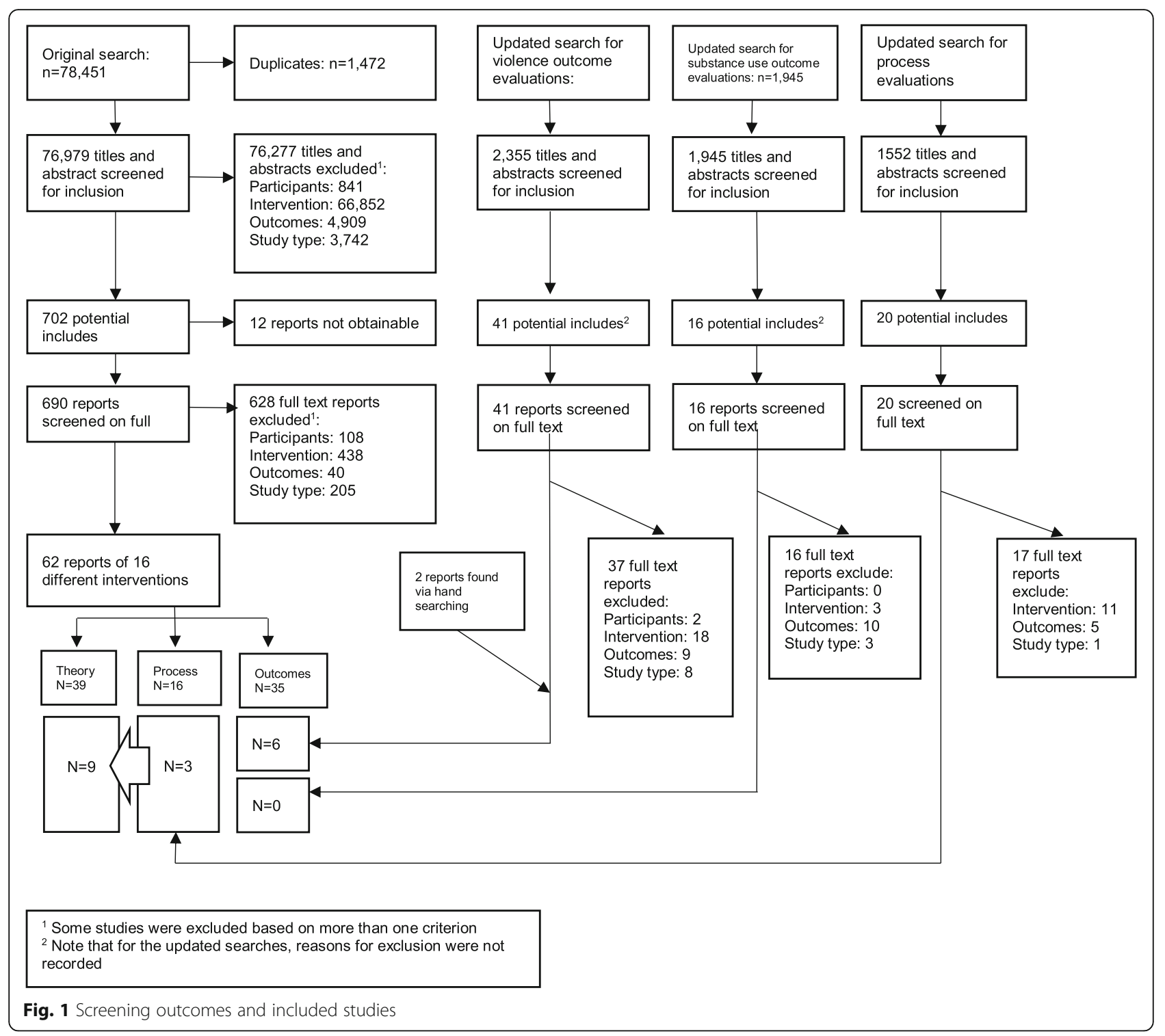

The remainder of the results present our synthesis of theories of change for the overall category of interventions integrating health and academic education to prevent violence or substance use. Because of the poor inter-rater consistency of quality appraisal, we do not refer below to summaries of the quality of theories of change in the synthesis. Our synthesised theories of change for each individual intervention are not reported here but can be found in Additional file 1.

\section{Programme inputs}

Our review focused on school-based interventions and these overwhelmingly involved health curricula delivered in classrooms. Some programmes also included after-school or out-of-school components, while others had whole-school or family components. As an example of a multi-component intervention, the Positive Action curriculum:

Teaches specific positive actions for the whole self: the physical, intellectual, social, and emotional areas.

Together, these make up the comprehensive set of skills for successful learning and living... The program trains teachers and parents to identify, teach, and reinforce positive thoughts, actions, and feelings about themselves by students and others in the school, leading to continual reinforcement of positive actions and enhanced student bonding with parents and school. ([58], pp.476-477)

Some interventions required the training of teachers or other staff in delivery of the curriculum. Some 
curricula were externally facilitated and therefore no internal training of school staff was required.

Curricula addressed a wide variety of topic areas and desired skills. Of note, only two interventions dealt directly with substance use. Most curricula concentrated on conflict resolution, problem-solving skills and social-emotional skills like emotional intelligence and empathy in students, as an example from 4Rs indicates here:

The approach of embedding social-emotional learning and conflict resolution lessons in a balanced literacy delivery strategy, and research tying together the social-emotional and academic domains, support our expectation for longer term effects on behavior and academic achievement. ([59], p. 536)

\section{Mechanisms of change: improving health by eroding boundaries}

Through our application of a meta-ethnographic approach, an overarching line of argument that emerged from our analysis was that eroding boundaries at multiple and mutually reinforcing levels-by integrating academic and health education, by strengthening relationships between teachers and students, by generalising learning from classrooms to the wider school environment, and by ensuring consistent messages from schools and families-will lead to the development of a community of engaged students oriented towards pro-social behaviour and away from substance use, violence and other risk behaviours.

\section{Eroding boundaries between health and academic education}

A recurring theme was that interventions integrated and thereby eroded the boundaries between health and academic education. There were two types of integration, which we have defined here as 'full' integration and 'partial' integration.

In the full integration approach, health education was completely integrated into existing academic subject classes, aiming to build both academic and health knowledge and skills seamlessly and simultaneously. An example of this integration is DRACON [60], which used drama classes as a medium for building drama skills while also aiming to enable children to learn conflict resolution skills intended as a means of reducing aggression. Another example of a fully integrated curriculum was 4 Rs, which 'uses high-quality children's literature as a springboard for helping students gain skills and understanding in several areas including handling anger, listening, cooperation, assertiveness, and negotiation (...) ensuring students understand the primary themes of the story and allowing them to connect the themes to their own lives.' ([61], p. 414)
In the second approach, partial integration, interventions addressing substance use or violence were delivered within the normal school curriculum but were treated as discrete modules or programmes, not weaved into normal academic education. What made them integrated' was simply that while the interventions mainly addressed the knowledge and skills necessary to avoid substance use and violence, they also included some academic elements, regarded as important to address the range of determinants of substance use or violence.

An example of this type of integration is PATHS, which, in its grade five curriculum, included literacy components. However, the PATHS curriculum is primarily focused on building non-academic skills, and although the curriculum is delivered during normal school hours within academic classes, these classes are distinct from the normal academic curriculum.

Language arts (both reading and writing) are bridged to PATHS in most lessons by including supplementary suggestions for teachers to utilize such things as quality children's literature to reinforce lesson concepts. Further, one of the chapters in the Instructional Manual provides many ideas for how teachers can directly tie PATHS concepts to language arts, social studies/history, and other subject areas. ([62], p. 404)

Two common themes emerged in the synthesis as reasons why integration of health and academic curricula was attempted. The more pragmatic rationale referred to the decreasing time in the school day dedicated to teaching topics such as health, wellness or conflict resolution. This theme resonated particularly strongly in American programmes delivered after the 2001 No Child Left Behind Act [63]. This act emphasised academic performance on standardised tests, which was often cited in practice as causing schools to focus less on other aspects of student development. Authors discussed how such interventions:

\section{Evolved in response to the tension between the movement to reform education between standards- based accountability with its focus on academic achievement, on the one hand (e.g., the policy and practice zeitgeist promoted by the No Child Left Behind Act of 2001), and social and character development, on the other. ([51], p. 156)}

A second, more scientific theme suggested that academic performance and health outcomes could be improved simultaneously and that these outcomes were mutually reinforcing. The extract below from Roots of Empathy offers an example of this kind of discussion. 
Schools can be reassured by scientific and pragmatic evidence that time spent implementing [social-emotional learning (SEL)] will enhance the academic success of students (...) Current research shows that SEL programs contribute to the academic success of students as well as to their health and wellbeing. ([64], p. 54)

In discussions of the rationale for integration, one additional opinion on the state of health education in schools was expressed by investigators of The Gatehouse Project, who maintained that there was a new convergence of academic and health mandates in schools, which may reflect the particular policy context in Australia.

There are signs that health and educational agendas are converging. There has, for example, been an increasing interest in the forms of schooling that might best meet the educational needs of early adolescents. The call for reform (...) has been driven by the identification of alienation or disengagement of young people as the major barrier to educational success. ([65], p. 588)

Two additional points concerning the rationale for integration were raised to a much lesser extent, but are likely relevant to most of these programmes. These are as follows: that an integrated curriculum provides opportunities for repetition and reinforcement of health concepts and that, when health messages are not as overt-if explored through literature or other subject matter-students may be less resistant to them [66].

Optimal learning occurs when information is embedded in meaningful contexts, applications and multiple representations are provided, and there are opportunities for learners to generate personally relevant questions. ([67], p. 220)

Several interventions aimed to integrate health and academic education by making learning more experiential, rooting learning in active participation and providing opportunities for practical skill development. For example, in the I-LST programme, 'teachers were also encouraged to be certain that the activities were developmentally appropriate and that the lessons included facilitation, coaching and behavioral rehearsal of skills as well as student-centred learning strategies' ([67], p. 222).

\section{Eroding boundaries between teachers and students}

The role of the teacher was central to programme-driven change at all levels (e.g. student, classroom, whole school and family). A recurring theme was that interventions aimed to transform relationships between students and teachers and thus establish a better classroom climate. While this theme resonates with the concept of boundary erosion, it also suggests an elaboration of the latter is required, as has previously been argued [68]. By boundary erosion, what we mean is not an erosion of source of differences between staff and students or a challenge to disparities of power but rather a transformation of the quality and strengthening of relationships so that these move beyond merely the instrumental task of academic education and embrace more affective dimensions and students' overall development. In the included studies, the positive relationships between teachers and students were often seen as increasing student connectedness to the classroom and school, and invoking a sense of responsibility in students to act in a way that is beneficial for themselves, their peers and their teacher.

Teacher-student relationships are a joint function of the unique characteristics of children (e.g., their social-cognitive attributions and problem-solving style) and teachers (e.g., their social-emotional abilities and experiences of job stress and burnout) and the cultural norms, values, and practices they bring to the relationship and to the classroom. Together these characteristics contribute to the climate of the classroom. ([51], p.154)

The establishment of student-teacher bonds was regarded as key to normalising positive behaviours in students.

Once strong bonds are established, individuals will tend to behave in a manner consistent with the norms and values of the individuals and groups with whom they associate. In turn, stronger prosocial bonds support positive belief formation against antisocial behaviors (e.g. adolescent substance use). ([69], p. 700)

Teachers' relationship to the curricula they delivered, specifically, their internalisation of the curriculum's messages was regarded as important. Teachers invested in the integrated curriculum were expected to role-model desired behaviours expressed within the curriculum, further normalising these for students.

When teachers embrace and practice the program's principles and implementation strategies, they establish a set of expectations and norms for behaviors in their classrooms, and children begin using those skills and behaviors. ([51], p. 157)

Steps to Respect highlights the role of teachers in changing social norms for young people by changing their attitudes about, in this instance, bullying. 
Because bullying is a social process strongly influenced by the reactions and behaviors of peers, the program seeks to change attitudes about the acceptability of bullying through clearly labeling bullying behavior as unfair and wrong, increasing empathy for students who are bullied, and educating students about their responsibilities as bystanders to bullying. ([70], p. 425)

\section{Eroding boundaries between classroom and the wider school} Another recurring theme was the importance of interventions aiming to generalise learning from the classroom to the wider school environment. Engaging students outside of the classroom enabled them to reinforce positive behaviours and to increase their broader sense of connectedness with the school.

Having opportunities at multiple levels for skill reinforcement was emphasised by several programmes. At the school level, providing an environment to reinforce skills or behaviours developed through the curriculum could be achieved by involving non-teaching members of staff in some of the programme training, as in the 4 Rs intervention.

Ecologically oriented programs emphasize not only the teaching of skills, but also the creation of meaningful real-life opportunities to use skills and the establishment of structures to provide reinforcement for effective skill application. ([62], p. 399)

Positive reinforcement of pro-social skill demonstration could occur via explicit rewards or simply by students feeling good about themselves as a result of practising such behaviours. Positive reinforcement was often described as being strengthened through opportunities for demonstration in different areas of life leading to further reinforcement. Demonstration of positive behaviours was then felt to contribute to a positive sense of self, leading to further positive behaviours. Such processes were regarded as enabling internalisation of curriculum content by students.

PATHS highlights that, 'internalization is the primary process utilized in the development of an individual's conscience. When the outcome is positive, the conscience...works as a powerful system through which a person can 'take ownership' and achieve mastery over his or her own impulses and actions.' ([62], p. 401)

Many interventions, either directly or indirectly, sought to improve students' sense of connectedness to the school environment. A sense of connectedness and bonding with the school was seen to be linked to overall emotional wellbeing and a sense of security experienced by students in school.

The extent to which an individual has robust social ties is likely to have a direct influence on self-concept and sense of belonging, and, in turn, reactions to social stressors. Conversely, the experience of ongoing insecurity and threat has a detrimental effect on emotional wellbeing. An individual's capacity to deal with adversity is in part dependent on the availability of support in the immediate social environment, as well as the skills he or she has for making appropriate connections at times of stress. ([65], p. 587)

Connectedness was also seen to help foster better academic learning as the school becomes a more positive environment that students invest in.

Eroding boundaries between schools and families Some multi-level interventions included family components, which were theorised to provide opportunities for students to apply their learning to engage in pro-social behaviours, in particular, conflict resolution at home, and to receive positive reinforcement. Some interventions also aimed to provide training to parents so they might role-model positive behaviours. For example, from the KAT programme:

Where parents or other community members are actively involved in programmes, they are exposed to the same health-behaviour messages as younger participants and, if they accept those messages, can reinforce them through their own actions, behaviours and attitudes. ([71], p. 3)

Interpreting this sub-theme in the light of our overarching theme of boundary erosion, these interventions can be viewed as aiming to ensure consistent messaging and erosion of boundaries between learning and behaviour at school and at home.

\section{Additional mechanisms to reduce substance use}

Although the notion of boundary-erosion offered a useful overarching theme to structure our analysis, some mechanisms that emerged from our synthesis, though they did not contradict the existing thematic structure, could not easily be incorporated within it. As well as cultivating pro-social skills and relationships outlined above, additional key mechanisms of change found in the synthesis for interventions that primarily aimed to reduce substance use involved educating students about substance use and providing training in resistance skills (that is, teaching students to resist peer pressure to use substances). 
For example, within Positive Action:

The program targets the reduction of students' healthcompromising and other negative behaviors (e.g., substance abuse, violence, disciplinary referrals, suspensions), while simultaneously enhancing healthenhancing and other positive behaviors (e.g., honesty, time management) and behavioral attributions directed at the self (...) and social relationships (...), with these leading to improved school-related performance. ([72], p. 2)

\section{Hypothesised intervention outcomes}

Most of the interventions aimed to reduce aggression, violence or bullying in young people through the mechanisms outlined above, usually in combination. Proximal outcomes commonly highlighted across the interventions leading to reduced violence included the development of pro-social skills, emotional intelligence (broadly understood as self-awareness) and self-management (encompassing managing emotions, emotional regulation, and responding constructively to bullying and conflict). These proximal outcomes were theorised as arising out of the mechanisms described above. Most authors made an overall assumption that anti-social behaviours occur because of a deficit in these social and emotional skills.

For example, the Roots of Empathy programme was reported to have, significantly improved the attitudes, knowledge and social emotional competencies of all participating teachers and children. A decrease in the frequency of bullying and an increase in pro-social behaviours were reported by all participants.' ([64], pp. 68-69)

Whereas the Positive Action programme was:

Designed to target the enhancement of positive behaviors and behavioral attributions directed at the self (e.g. self-responsibility, positive self-concept) and social relationships (e.g. conflict resolution, respect, kindness), while simultaneously reducing students' negative behavioral problems (e.g. substance abuse, disciplinary referrals, suspensions), with these leading to improved school-related performance (e.g. improved attendance, academic achievement). ([72], p. 73)

\section{Discussion}

\section{Summary of the synthesis}

The interventions within this review aimed to integrate and thus erode boundaries between academic and health education. They also generally aimed to train teachers to model positive behaviours, reinforce such behaviours among students and enhance their relationships with students. We characterised these as fitting within an overarching theme of boundary erosion, but in doing so clarified that this means transforming relationships from being instrumentally focused on academic learning to being more affective and focused on students' broader development. This work in the classroom was supported by other components delivered at multiple levels (e.g. the overall school environment and the family), which aimed to ensure that learning and reinforcement of positive behaviours occurred beyond the classroom. We interpreted this mode of delivery as a mechanism that aimed to erode boundaries between what occurred in classrooms and other settings such as the wider school and students' families. Through these multiple, but theoretically related, mechanisms, interventions were thus intended to promote experiential learning, the practising and reinforcement of positive behaviours and enhanced relationships between teachers and students and between students and their pro-social peers. In turn, it is theorised that these will provide students with various attributes necessary to reduce engagement in substance use and violence as well as to increase academic attainment. These attributes include the knowledge and skills necessary to avoid substance use and prevent conflict, the attitudes and social norms supportive of such behaviours and students' sense of security within and positive connectedness to their classrooms and schools.

\section{Strengths and limitations of the review}

Overall strengths of the review include having a very comprehensive search strategy, which we believe resulted in maximising our identification of studies relevant to our research questions, as well as a structured approach to the synthesis of theories of change.

Although other existing theory syntheses have focused on some of the same programmes that we have covered here [36, 37], they did exclusively focus on interventions that integrate health and academic learning. Furthermore, through robust systematic review methods, we have achieved more breadth and depth in the analyses of these theories. In contrast to other reviews [40, 41], we chose to focus on theories of change presented in empirical reports or theory reports linked to empirical studies. This decision reflected our (correct) expectation that there would currently be no stand-alone theoretical literature on this newly emergent category of intervention.

Employing meta-ethnographic reciprocal translation allowed us to draw out synergetic ideas from each theory that supported the emergent overarching theme of boundary erosion for health promotion in schools. Authors presented their views of theories that influence the interventions they introduced and, in some instances, explicitly offered theories of change. The use of meta-ethnography allowed us to engage with authors' 
descriptions of theories of change as their own interpretation of the world, rather than as secondary constructs based on previous evidence, which was helpful to overcome some of the challenges of applying qualitative synthesis approaches to theory data. Further, the application of multiple methods of qualitative synthesis and the use of an existing theory of schools and health promotion enabled us to develop a deeper analysis of the common mechanisms of action underlying how the interventions in our review are intended to work.

All reports included were appraised for quality and assigned a score based on the criteria indicated in our methods. There was some disagreement between the two reviewers carrying out the quality assessment. As mentioned, there was little guidance available from other studies as to how to resolve challenges encountered in this appraisal. We encountered four main challenges appraising theories introduced through this literature. First, with regards to generalisability, we recognised that many theories of change are programme-specific and thus not intended to be generalisable. Second, we aimed to see if theories were based on existing evidence and/or tested empirically. However, we found that often programme theories drew from multiple existing theories, impeding any simple judgement on the overall evidence base. Third, it was clear that different authors assumed different levels of prior understanding of constructs among their readers, as some provided detailed explanations of constructs and their relationships, while others proceeded as if these were widely understood. It was difficult to decide how to assess the clarity of constructs that were not explained but which we assumed many readers would indeed be familiar with, such as social norms. Finally, we pragmatically used quantitative scores to represent the overall quality of studies and determine which studies we synthesised first despite our tool not having been validated to do this. Overall, as has been noted by authors elsewhere [49], despite carrying out a formal appraisal process, no reports were excluded and all contributed-albeit to different degrees-to the synthesis on the basis of their conceptual strength despite methodological weaknesses.

To achieve a standardised system for appraisal, all reports were treated in the same way, although we were aware that theory was described to different extents depending on each report's objectives, audience, journal of publication and so forth. Therefore, in some cases, authors' having more text dedicated to describing theory inevitably led to a higher quality score as well as greater weight being given to their report in our theory synthesis. Furthermore, where there were multiple reports about a single intervention, some of these scored higher in quality assessment, compared to studies in which only one paper reported on theory. Within those assessments, greater weight was given to the studies of higher quality.
These challenges indicate that there continues to be a need to refine criteria. For fields where there is little previous theoretical cohesion, it may be necessary to synthesise every theory in equal measure, particularly since the threat of biasing of syntheses is so much less than is the case with synthesis of empirical evidence.

In terms of applying existing theory to our analysis, our identification of the erosion of boundaries as an overarching theme was informed by our previous reading of the theory of human functioning and school organisation [57]. This theory proposes that young people engage in healthy behaviours when they feel committed to school in terms of learning and as a social community. The theory further suggests that this is most likely to occur in schools that 'erode boundaries' (or establish enhanced connections) between, for example, academic and broader learning, teachers and students and schools and their surrounding communities. While not cited by the theoretical literature included in this review, this theory resonates with many of the themes apparent in our initial coding.

Thinking about erosion of boundaries is, in our view, a helpful way of interpreting these theories collectively, but it did require some elaboration of what is meant by boundary erosion in the case of teacher-student relationships (where it meant a transformation of the strength and quality of relationship rather than a negation of all differences and disparities) and student-student relationships (where the emphasis was on building bonds with pro-social students, not all students, and resisting normalised peer behaviour around risk-taking).

The body of literature from which we drew our synthesis raises some additional issues and limitations. In relatively few instances did authors refer to the importance of intervening at specific developmental stages to affect desired changes, so the age at which interventions should be introduced to students did not feature in the mechanisms of change we have proposed. Of note, those interventions intended to reduce substance use focused on adolescents in secondary school, as did those that aimed to reduce conflict and bullying. Interventions like PATHS and Roots of Empathy, which aim to develop social and emotional learning skills and emotional intelligence more broadly, were seen to be of greater use when introduced to younger students. It is unclear whether it is a strength or a weakness of these programmes that some are presented as largely universal across grades, while others are suggested to be age group-specific.

Although some programmes aimed to target both violence and substance abuse, we found in the synthesis that much more explanation and detail was offered about the former, which might affect the salience of our proposed synthesis in some contexts. 
Furthermore, there was a general assumption in the literature that risk behaviours arise from deficits in individual knowledge, social and emotional skills and attitudes, albeit within a broader social and institutional context. However, others have argued that behaviours such as violence or substance use emerge as active, symbolically significant practices among young people who are, for complex structural and institutional reasons, disengaged from schools in terms of learning and the social community $[56,73]$. Thus, behaviours such as smoking, drug use or violence might occur not merely through deficits but as a result of rationally chosen and socially sanctioned decisions, albeit perhaps within a context of limited choices. The lack of consideration of such mechanisms within programme theories in this review might lead such interventions to fail to address important influences on young people's substance use and violence. Moreover, despite some mention of the importance of relationships outside the classroom, the classroom environment is overwhelmingly the focus of these interventions, which may fail to address the broader context in which young people develop behaviours.

Finally, most theories did not consider how moderating factors might interact with mechanisms of change as would be the case with theories informed by realist ontologies [74]. Haegerich and Metz [37] extrapolated a summary of moderating factors for some of the same interventions in our synthesis, which included student (e.g. socioeconomic status, ethnicity, gender, intervention dosage) and contextual (e.g. school, family, cultural or policy) characteristics. However, discussions of the role of these factors were consistently underdeveloped in most theories in our synthesis, despite potential implications for programmes' impacts and the extent to which they might translate between different populations and settings.

\section{Implications for future research and policy}

This review of theoretical literature provides a clearer definition of this novel and potentially important category of intervention, and an insight into the common mechanisms through which diverse real-life examples of integration are intended to work. Centring on the notion of interventions eroding boundaries within and beyond schools will be useful when we come to synthesise empirical evidence from process and outcome evaluations of these same interventions, as we will be able to categorise evaluated interventions by their main intended mechanism of action.

In terms of policy, this intervention type presents great promise as a means of addressing health in busy school timetables, addressing health determinants relating to health knowledge and skills and school engagement and education more generally. Here, we have defined and added clarity to these interventions and their theoretical underpinnings. We are in the process of synthesising process and outcome evaluations of these interventions to determine their feasibility and effectiveness in reducing violence and substance use.

\section{Conclusion}

Here, we have applied Markham and Aveyard's model of boundary erosion to explain the social and psychological processes that underlie interventions that integrate academic and health education for reduced substance use and/or violence. In particular, eroding boundaries between health and academic education, teachers and students, classrooms and the wider school and schools and families were seen to be the most critical to establishing new frameworks of family, classroom or school organisation that are conducive to promoting both academic and social-emotional outcomes. A better understanding of the theory underlying these approaches should support their further development and evaluation.

\section{Additional file}

Additional file 1: Synthesised theories of change for each individual intervention. (DOCX 1841 kb)

\section{Abbreviations \\ 4Rs: Reading, Writing, Respect, and Resolution; I-LST: Integrated Life Skills Training; KAT: Kids, Adults Together; LIFT: Linking the Interests of Families and Teachers; LRHC: Learning to Read in a Healing Classroom; \\ PATHS: Promoting Alternative Thinking Strategies; PRISMA: Preferred Reporting Items for Systematic Reviews and Meta-Analyses; SEL: Social and emotional learning; SS: Second Step}

\section{Acknowledgements}

The authors wish to acknowledge Clare Stansfield who carried out the database searches of studies included in this review. We are also grateful for the technical support we received from the staff at the EPPI-Centre.

\section{Funding}

This project is funded by a grant from the National Institute for Health Research Public Health Research programme (grant PHR 14/52/15). This report presents independent research commissioned by the National Institute for Health Research (NIHR). The views and opinions expressed by authors in this publication are those of the authors and do not necessarily reflect those of the NHS, the NIHR, MRC, CCF, NETSCC, the Public Health Research programme or the Department of Health.

Availability of data and materials

Data sharing is not applicable to this article as no data sets were generated or analysed during the current study.

\section{Authors' contributions}

CB led the design and conduct of the review. AF, GM, JT and RC contributed to the design of this review. $T$ and $C B$ data extracted and quality assessed all included studies. $T$ and SP led the analysis, overseen by CB. TT and SP wrote the first draft of this paper. All authors read, approved and contributed to editing further drafts.

\section{Ethics approval and consent to participate}

This project was approved by the research ethics committee of UCL Institute of Education (ethics approval reference REC 746). The project complied with the Social Research Association's ethical guidelines and guidance from the National Coordinating Centre for Public Engagement. 


\section{Consent for publication}

Not applicable.

\section{Competing interests}

The authors declare that they have no competing interests.

\section{Publisher's Note}

Springer Nature remains neutral with regard to jurisdictional claims in published maps and institutional affiliations.

\section{Author details}

'Department of Public Health, Environments and Society, London School of Hygiene and Tropical Medicine, 15-17 Tavistock Place, London WC1H 9SH, UK. ${ }^{2}$ Division of Health Sciences, Warwick Medical School, University of Warwick, Coventry CV4 7AL, UK. ${ }^{3}$ Evidence for Policy and Practice Information and Co-ordinating Centre (EPPI-Centre), Social Science Research Unit, University College London Institute of Education, WC1H ONR, London, UK. ${ }^{4}$ Development and Evaluation of Complex Interventions for Public Health Improvement (DECIPHer), School of Social Sciences, Cardiff University, Cardiff CF10 3WT, UK. ${ }^{5}$ Department of Population Health Sciences, University of Bristol, 39 Whatley Road, Bristol BS8 2PS, UK.

\section{Received: 18 April 2018 Accepted: 30 October 2018}

Published online: 13 November 2018

\section{References}

1. Faggiano F, Vigna-Taglianti FD, Versino E, Zambon A, Borraccino A, Lemma P. School-based prevention for illicit drugs' use. Cochrane Database Syst Rev. 2005;2:CD003020.

2. Farrington DP, Ttofi MM. School-based programs to reduce bullying and victimization. U. S. Department of Justice: Washington (DC); 2009.

3. Foxcroft DR, Tsertsvadze A. Cochrane review: universal school-based prevention programs for alcohol misuse in young people. Cochrane Database Syst Rev. 2012:7(2):450-575.

4. Thomas RE, Perera R. School-based programmes for preventing smoking. Cochrane Database Syst Rev. 2006:4:CD001293.

5. Vreeman RC, Carroll AE. A systematic review of school-based interventions to prevent bullying. Arch Pediatr Adoles Med. 2007;161(1):78-88.

6. Demissie Z, Brener N, McManus T, Shanklin S, Hawkins J, Kann L. School health profiles 2012: characteristics of health programs among secondary schools. Atlanta: Centers for Disease Control and Prevention; 2013.

7. Frey KS, Hirschstein MK, Guzzo BA. Second step preventing aggression by promoting social competence. J Emot Behav Disord. 2000;8(2):102-12.

8. Visscher AJ. Public school performance indicators: problems and recommendations. Stud Educ Eval. 2001;27(3):199-214.

9. Bonell C, Humphrey N, Fletcher A, Moore L, Anderson R, Campbell R. Why schools should promote students' health and wellbeing. BMJ. 2014 348(7958):g3078.

10. Moore GF, Littlecott HJ, Fletcher A, Hewitt G, Murphy S. Variations in schools' commitment to health and implementation of health improvement activities: a cross-sectional study of secondary schools in Wales. BMC Public Health. 2016;16:138.

11. Formby E, Coldwell M, Stiell B, Demack S, Stevens A, Shipton L, Wolstenholme C, Willis B. Personal, social, health and economic (PSHE) education: a mapping study of the prevalent models of delivery and their effectiveness. Sheffield: Sheffield Hallan University; 2011.

12. Wright $G$, Ainsworth P. Plastered evaluation: part of It's not OK! Violence prevention education programme. Ariel Trust: Liverpool; 2008

13. Durlak JA, Weissberg RP, Dymnicki AB, Taylor RD, Schellinger KB. The impact of enhancing students' social and emotional learning: a meta-analysis of school-based universal interventions. Child Dev. 2011;82(1):405-32.

14. Zins JE, Bloodworth MR, Weissberg RP, Walberg HJ. Building academic success on social and emotional learning: what does the research say? New York: Teachers College Press; 2004.

15. Hibell B, Guttormsson U, Ahlström S, Balakireva O, Bjarnason T, Kokkevi A, et al. The 2011 ESPAD report: substance use among students in 36 European countries. The Swedish Council for Information on Alcohol and Other Drugs: Stockholm; 2011.

16. Masterman P, Kelly A. Reaching adolescents who drink harmfully: fitting interventions to developmental reality. J Subst Abus Treat. 2003;24:347-55.
17. Dunstan S. General lifestyle survey overview. Office for National Statistics: Newport; 2012.

18. Beautrais A, Joyce $P$, Mulder R. Cannabis abuse and serious suicide attempts. Addiction. 1999:94:1155-64.

19. Charlton J, Kelly S, Dunnell K, Evans B, Jenkins R. Suicide deaths in England and Wales: trends in factors associated with suicide deaths. Popul Trends. 1993;71:35-42.

20. Thomas J, Kavanagh J, Tucker H, Burchett H, Tripney J, Oakley A. Accidental injury, risk-taking behaviour and the social circumstances in which young people (aged 12-24) live: a systematic review. London: The Evidence of Policy and Practice Information and Co-ordinating Centre (EPPI-Centre); 2007.

21. Calafat A, Blay N, Juan M, Adrover D, Bellis MA, Hughes $K$, et al. Traffic risk behaviors at nightlife: drinking, taking drugs, driving, and use of public transport by young people. Traffic Inj Prev. 2009;10:162-9.

22. Drugs Strategy Directorate. Updated drug strategy 2002. London: Stationery Office: Home Office; 2002.

23. Jayakody A, Sinha S, Curtis K, Roberts H, Viner R. Smoking, drinking, drug use, mental health and sexual behaviour in young people in East London. London: Department of Health \& Teenage Pregnancy Unit; 2005.

24. Jessor RDJ, Costa FM. Beyond adolescence: problem behaviour and young adult development. Cambridge: Cambridge University Press; 1994

25. Krug EGMJ, Dahlberg LL, Zwi AB. The world report on violence and health. Lancet. 2002;360:1083-8.

26. Scott SKM, Henderson J, Maughan B. Financial cost of social exclusion: follow up study of antisocial children into adulthood. BMJ. 2001:323:191.

27. Beinart SAB, Lee S, Utting D. Youth at risk? A National Survey of risk factors, protective factors and problem behaviour among young people in England Scotland and Wales (JRF findings 432). York: Joseph Rowntree Foundation; 2002

28. Bender D, Losel F. Bullying at school as a predictor of delinquency, violence and other anti-social behaviour in adulthood. Crim Behav Ment Health. 2011;21:99-106.

29. Olweus D. Bullying at school: what we know and what we can do. Maidenhead: Blackwell; 1993.

30. Catalano RF, Kosterman R, Hawkins JD, Newcomb MD, Abbott RD. Modeling the etiology of adolescent substance use: a test of the social development model. J Drug Issues. 1996;26(2):429-55.

31. Kaplow JB, Curran PJ, Dodge KA. Child, parent, and peer predictors of earlyonset substance use: a multisite longitudinal study. J Abnorm Child Psych. 2002;30(3):199-216.

32. Trinidad DR, Johnson CA. The association between emotional intelligence and early adolescent tobacco and alcohol use. Pers Indiv Differ. 2002;32(1):95-105

33. Bereiter C. Situated cognition and how to overcome it. In: Kirshner D, Whitson JA, editors. Situated cognition: social, semiotic, and psychological perspectives. Hillsdale: Erlbaum; 1997. p. 281-300.

34. Bier MC, Zwarun L, Warren VF. Getting universal primary tobacco use prevention into priority area schools a media literacy approach. Health Promot Pract. 2011;12(6 suppl 2):152S-8S.

35. Kupersmidt JB, Scull TM, Benson JW. Improving media message interpretation processing skills to promote healthy decision making about substance use: the effects of the middle school media ready curriculum J Health Commun. 2012;17(5):546-63.

36. Flay B, Berkowitz MW, Bier MC. Elementary school-based programs theorized to support social development, prevent violence, and promote positive school climate: description and hypothesized mechanisms of change. J Res Character Educ. 2009;7(2):21-49.

37. Haegerich TM, Metz E. The social and character development research program. J Res Character Educ. 2009;7(2):1-20.

38. Craig P, Dieppe P, Macintyre S, Michie S, Nazareth I, Petticrew M. Developing and evaluating complex interventions: the new Medical Research Council guidance. BMJ. 2008;337:a1655

39. Development and Evaluation of Complex Interventions for Public Health Improvement (DECIPHer). Is it possible to synthesise theory? http://decipher. uk.net/synthesising-theory/. Accessed 15 Jan 2017.

40. Bonell C, Fletcher A, Jamal F, Wells H, Harden A, Murphy S, Thomas J. Theories of how the school environment impacts on student health: systematic review and synthesis. Health Place. 2013;24:242-9. 
41. Bonell C, Hinds K, Dickson K, Thomas J, Fletcher A, Murphy S, MelendezTorres GJ, Bonell C, Campbell R. What is positive youth development and how might it reduce substance use and violence? A systematic review and synthesis of theoretical literature. BMC Public Health. 2016;16:135.

42. Pound P, Campbell R. Exploring the feasibility of theory synthesis: a worked example in the field of health related risk-taking. Soc Sci Med. 2015;124:57-65.

43. Pound P, Campbell R. Locating and applying sociological theories of risktaking to develop public health interventions for adolescents. Health Sociol Rev. 2015;24(1):64-80.

44. Barnett-Page $E_{1}$ Thomas J. Methods for the synthesis of qualitative research: a critical review. BMC Med Res Methodol. 2009:9(1):1.

45. Thomas J, Harden A. Methods for the thematic synthesis of qualitative research in systematic reviews. BMC Med Res Methodol. 2008;8(1):1.

46. Nye E, Melendez-Torres G, Bonell C. Origins, methods and advances in qualitative meta-synthesis. Rev Educ. 2016;4(1):57-79.

47. Campbell M, Egan M, Lorenc T, Bond L, Popham F, Fenton C, Benzeval M. Considering methodological options for reviews of theory: illustrated by a review of theories linking income and health. Syst Rev. 2014;3(1):1

48. Campbell R, Pound P, Pope C, Britten N, Pill R, Morgan M, Donovan J. Evaluating meta-ethnography: a synthesis of qualitative research on lay experiences of diabetes and diabetes care. Soc Sci Med. 2003;56(4):671-84.

49. Campbell R, Pound P, Morgan M, Daker-White G, Britten N, Pill R, Yardley L, Pope C, Donovan J. Evaluating meta ethnography: systematic analysis and synthesis of qualitative research. Health Technol Assess. 2011;15(43):1-164.

50. Moher D, Liberati A, Tetzlaff J, Altman DG. The PRISMA Group: Preferred Reporting Items for Systematic Reviews and Meta Analyses: The PRISMA Statement. PLoS Med. 2009:6(7):e1000097.

51. Brown JL, Jones SM, LaRusso MD, Aber JL. Improving classroom quality: teacher influences and experimental impacts of the 4Rs program. J Educ Psychol. 2010;102(1):153.

52. Jones SM, Brown JL, Aber JL. Classroom settings as targets of intervention and research. In: Shinn M, Yoshikawa $H$, editors. Toward positive youth development: transforming schools and community programs. Oxford: Oxford University Press; 2008

53. Britten N, Campbell R, Pope C, Donovan J, Morgan M, Pill R. Using meta ethnography to synthesise qualitative research: a worked example. J Health Serv Res Po. 2002;7(4):209-15.

54. Noblit GW, Hare RD. Meta-ethnography: synthesizing qualitative studies. London: Sage Publications; 1988.

55. Schutz A. The Hague: Martinus Nijhoff Collected Papers; 1962. p. 2

56. Jamal F, Fletcher A, Harden A, Wells H, Thomas J, Bonell C. The school environment and student health: a systematic review and metaethnography of qualitative research. BMC Public Health. 2013;13(1):798.

57. Markham WA, Aveyard P. A new theory of health promoting schools based on human functioning, school organisation and pedagogic practice. Soc Sci Med. 2003:56(6):1209-20.

58. Flay $B$, Allred C. The Positive Action Program: improving academics, behavior, and character by teaching comprehensive skills for successful learning and living. In: Loval T, Toomey R, Clement N, editors. International Research Handbook on Values Education and Student Wellbeing. New York: Springer; 2010. p. 1040.

59. Jones SM, Brown JL, Lawrence AJ. Two-year impacts of a universal schoolbased social-emotional and literacy intervention: an experiment in translational developmental research. Child Dev. 2011;82(2):533-54.

60. Malm B, Löfgren $\mathrm{H}$. Empowering students to handle conflicts through the use of drama. J Peace Educ. 2007;4(1):1-20.

61. Aber L, Brown JL, Jones SM, Berg J, Torrente C. School-based strategies to prevent violence, trauma, and psychopathology: the challenges of going to scale. Dev Psychopathol. 2011;23(2):411-21.

62. Greenberg $M$, Kusché $C$. Building social and emotional competence: the PATHS curriculum. In: Jimerson S, Furlong M, editors. Handbook of school violence and school safety. New York: Taylor \& Francis Group; 2006. p. 712.

63. U. S. Department of Education. No Child Left Behind Act https://www.gpo. gov/fdsys/pkg/PLAW-107publ110/html/PLAW-107publ110.htm. Accessed 15 Jan 2017

64. Cain G, Carnellor Y. 'Roots of Empathy': a research study on its impact on teachers in Western Australia. J Stud Wellbeing. 2008;2(1):52-73.

65. Patton GC, Glover S, Bond L, Butler H, Godfrey C, Pietro GD, Bowes G. The Gatehouse Project: a systematic approach to mental health promotion in secondary schools. Aust NZ J Psychiat. 2000;34(4):586-93.
66. Holcomb JD, Denk JP. An interdisciplinary English/health connection: promoting health awareness and healthy behaviors. J Health Educ. 1993: 24(sup1):S-36-41.

67. Bechtel $\amalg$, Vicary JR, Swisher JD, Smith EA, Hopkins AM, Henry KL, Minner D. An interdisciplinary approach for the integration and diffusion of substance abuse prevention programs. Am J Health Educ. 2006;37(4):219-25.

68. Bonell C, Fletcher A, Jamal F, Aveyard P, Markham W. Where next with theory and research on how the school environment influences young people's substance use? Health Place. 2016;40:91-7.

69. Brown EC, Catalano RF, Fleming CB, Haggerty KP, Abbott RD. Adolescent substance use outcomes in the Raising Healthy Children project: a two-part latent growth curve analysis. J Consult Clin Psych. 2005;73(4):699.

70. Brown EC, Low S, Smith BH, Haggerty KP. Outcomes from a schoolrandomized controlled trial of steps to respect: a bullying prevention program. School Psychol Rev. 2011;40(3):423.

71. Segrott J, Rothwell H, Hewitt G, Playle R, Huang C, Murphy S, Moore L, Hickman M, Reed $\mathrm{H}$. Preventing alcohol misuse in young people: an exploratory cluster randomised controlled trial of the Kids, Adults Together (KAT) programme. Public Health Research. 2015;3(15):1-188.

72. Beets M. Factors associated with the implementation fidelity of a schoolbased social and character development program: findings from the Positive Action Program, Hawai'i. Corvallis: Oregon State University; 2007.

73. Cousins LH. Toward a sociocultural context for understanding violence and disruption in black urban schools and communities. J Sociol Soc Welf. 1997;24:41.

74. Pawson R, Tilley N. Realistic evaluation. London: Sage; 1997.

75. Jones SM, Brown JL, Hoglund WL, Aber JL. A school-randomized clinical trial of an integrated social-emotional learning and literacy intervention: impacts after 1 school year. J Consult Clin Psych. 2010;78(6):829.

76. Sung J-A. Teachers' perceptions and experiences of the implementation of a social-emotional learning program in an inner-city public elementary school. New York: Columbia University; 2015.

77. Couch L. The bullying literature project: an evaluation of a class-wide bullying intervention program. Riverside: University of California Riverside; 2015

78. Wang C, Couch L, Rodriguez GR, Lee C. The Bullying Literature Project: using children's literature to promote prosocial behavior and socialemotional outcomes among elementary school students. Contemp Educ Psychol. 2015;19(4):320-9.

79. Wang C, Goldberg T. Using children's literature to decrease moral disengagement and victimization among elementary school students. Psych Schools. 2017;54:918-9311.

80. Zoller U, Weiss S. "Hashish and marijuana"—an innovative, interdisciplinary drug education curricular program for high schools. J Drug Educ. 1981;11(1):37-46.

81. Torrente C, Johnston B, Stakrey L, Siegman E, Shivshanker J, Weisenhorn N, et al. Improving the quality of school interactions and student wellbeing: impacts of one year of a school-based program in the Democratic Republic of the Congo. J Educ Emerg. 2015;215(1):48-91.

82. Aber J, Tubbs C, Torrente C, Halpin P, Johnston B, Starkey L, et al. Promoting children's learning and development in conflict-affected countries: testing change process in the Democratic Republic of the Congo. Dev Psychopathol. 2017;29(1):53-67.

83. DeGarmo DS, Eddy JM, Reid JB, Fetrow RA. Evaluating mediators of the impact of the Linking the Interests of Families and Teachers (LIFT) multimodal preventive intervention on substance use initiation and growth across adolescence. Prev Sci. 2009;10(3):208-20.

84. Eddy JM, Reid JB, Fetrow RA. An elementary school-based prevention program targeting modifiable antecedents of youth delinquency and violence linking the interests of families and teachers (LIFT). J Emot Behav Disord. 2000:8(3):165-76.

85. Eddy JM, Barkan SE, Lanham L. Preventive intervention to reduce youth conduct problems and substance use: linking the interests of families and teachers (LIFT). Washington (DC): American Psychological Association; 2015.

86. Reid JB, Eddy JM, Fetrow RA, Stoolmiller M. Description and immediate impacts of a preventive intervention for conduct problems. Am J Commun Psychol. 1999:27(4):483-518.

87. Reid JB, Eddy JM. Preventive efforts during the elementary school years: the linking the interests of families and teachers project. In: Reid JB, Patterson GR, Snyder J, editors. Antisocial behavior in children and adolescents: a developmental analysis and model for intervention. Washington (DC): American Psychological Association; 2002. p. 219-33. 
88. Wales A. Peaceful panels: using comics to teach anti-bullying to junior high school students. Prescott Valley: Northcentral University; 2013.

89. Beets MW, Flay BR, Vuchinich S, Acock AC, Li K-K, Allred C. School climate and teachers' beliefs and attitudes associated with implementation of the positive action program: a diffusion of innovations model. Prev Sci. 2008;9(4):264-75.

90. Beets MW, Flay BR, Vuchinich S, Snyder FJ, Acock A, Li K-K, Burns K, Washburn IJ, Durlak J. Use of a social and character development program to prevent substance use, violent behaviors, and sexual activity among elementary-school students in Hawaii. Am J Public Health. 2009;99(8):1438-45.

91. Lewis K. Evaluation of a social-emotional and character development program: methods and outcomes. Corvallis: Oregon State University; 2012.

92. Malloy M, Acock A, DuBois DL, Vuchinich S, Silverthorn N, Ji P, Flay BR. Teachers' perceptions of school organizational climate as predictors of dosage and quality of implementation of a social-emotional and character development program. Prev Sci. 2015;16(8):1086-95.

93. Crean HF, Johnson DB. Promoting Alternative Thinking Strategies (PATHS) and elementary school aged children's aggression: results from a cluster randomized trial. Am J Commun Psychol. 2013;52(1-2):56-72.

94. Kusché C, Greenberg M. The PATHS curriculum: promoting emotional literacy, prosocial behavior, and caring classrooms. In: Jimerson SR, Nickerson AB, Mayer MJ, Furlong MJ, editors. Handbook of school violence and school safety: international research and practice. 2nd ed. Abingdon: Routledge; 2012. p. 435-46

95. Catalano RF, Mazza JJ, Harachi TW, Abbott RD, Haggerty KP, Fleming CB. Raising healthy children through enhancing social development in elementary school: results after 1.5 years. J Sch Psychol. 2003;41(2):143-64.

96. Gordon M. Roots of empathy: responsive parenting, caring societies. Keio J Med. 2003;52(4):236-43.

97. Hanson JL. Teachers' beliefs about emotions in the classroom: relations to teacher characteristics and implementation of a social-emotional learning program: University of British Columbia; 2012.

98. Espelage D, Low S, Polanin J, Brown E. The impact of a middle school program to reduce aggression, victimization, and sexual violence. J Adolescent Health. 2013;53:180-6.

99. Espelage D, Low S, Polanin J, Brown E. Clinical trial of Second Step middleschool program: impact on aggression and victimization. J Appl Dev Psychol. 2015;37:52-63.

100. Espelage D, Low S, van Ryzin M, Polanin J. Clinical trial of Second Step middle school program: impact on bullying, cyberbullying, homophobic teasing, and sexual harassment perpetration. School Psychol Rev. 2015;44(4):464-79.

101. Farrell A, Mehari K, Kramer-Kuhn A, Mays S, Sullivan T. A qualitative analysis of factors influencing middle school students' use of skills taught by a violence prevention curriculum. J School Psychol. 2015;53(3):179-94.

102. Low S, Smolkowski K, Cook C. What constitutes high-quality implementation of SEL programs? A latent class analysis of second step implementation. Prev Sci. 2016;17(8):981-91.

103. Frey KS, Hirschstein MK, Edstrom LV, Snell JL. Observed reductions in school bullying, nonbullying aggression, and destructive bystander behavior: a longitudinal evaluation. J Educ Psychol. 2009;101(2):466.

104. Bond L, Butler H. The Gatehouse Project: a multi-level integrated approach to promoting wellbeing in schools. In: Killoran A, Kelly MP, editors. Evidence-based public health: effectiveness and efficacy. Oxford: Oxford University Press; 2010. p. 250-69.

105. Patton G, Bond L, Butler H, Glover S. Changing schools, changing health? Design and implementation of the Gatehouse Project. J Adolesc Health. 2003;33(4):231-9.

106. Jenson JM, Dieterich WA. Effects of a skills-based prevention program on bullying and bully victimization among elementary school children. Prev Sci. 2007:8(4):285-96.

Ready to submit your research? Choose BMC and benefit from:

- fast, convenient online submission

- thorough peer review by experienced researchers in your field

- rapid publication on acceptance

- support for research data, including large and complex data types

- gold Open Access which fosters wider collaboration and increased citations

- maximum visibility for your research: over $100 \mathrm{M}$ website views per year

At BMC, research is always in progress.

Learn more biomedcentral.com/submissions 